In spite of treatment no improvement in vision occurred. On May 16 the left pupil was inactive to light and by June 28 the fundus examination showed a secondary type of optic atrophy with some narrowing of the vessels. 'The right eye was normal throughout and, when seen in November 1935, was quite healthy, with $6 / 6$ vision after correction.

We infer that the massive lesion of the optic nerve was due to a direct spread of infection from a focus in the posterior ethmoidal cells and sphenoidal sinus. If so it must have occurred quite at the apex of the orbit. It will be noted that about a couple of months elapsed before the signs of a descending atrophy of the nerve were established by fundus examination. This length of time agrees pretty closely with what one expects in cases of direct tearing across of the nerve in cases of fractured base of the skull.

Perhaps after all our patient was fortunate in that the infection confined itself entirely to the nerve and that no backward spread into the cavernous sinus took place. The line that divides two such possibilities must be an exceedingly fine one.

\title{
THE EXTRACTION OF CATARACT BY THE ELECTRO-DIAFACO METHOD \\ (after Lopez Lacarrère of Madrid)
}

BY

\section{KhaliL}

CAIRO

Cataract is an eye disease which necessitates the removal of the affected lens. Of all the methods used from the time of Daviel, 1745 , till the present day, that which resulted in the extraction of the greater part of the diseased lens was considered best. Much better still are those methods which end in the removal of the lens in its capsule. Of the various intra-capsular methods known up to the present, one may mention (1) the category of expression -as Smith's method; (2) the category of suction-as by Barraquer's method; (3) the category of catching the lens with a blunt forceps, dislocating it, and extracting it out of the eye-as done by Elschnig, Kalt, Stanculeanu, Sinclair and others ; (4) the category of removal of lens after electro-coagulation-as originated by Jess and Lopez Lacarrère. It is out of the question that I would make a comparison between this last method and the various methods of intra-capsular extraction of cataract mentioned. However, it is as always useful to increase one's armamentarium in combating diseases. My object is to describe and demonstrate by pictures 
the method of Lopez Lacarrère of Madrid, which I have watched carried out by the originator himself in Madrid.

This subject is not brought forward with the pretension of its being the leading method at present, or as likely to replace other methods in future, for the extraction of immature or mature cataract, but it is presented as a novelty, which may, like many other novelties, come to our field with staggering feet at the beginning, obtaining a firmer footing later in life as it grows older, sometimes after modifications.

\section{History of the Operation}

As far as I know, no mention is made in the literature of extraction of cataracts by diathermy before the year 1931 .

At the annual meeting of the Ophthalmological Society of Egypt in March, 1933, our colleague, Dr. A. F. Togby, reported his experiments on animals with the method of extraction of the crystalline lens by electro-coagulation as performed in some European clinics which he visited.

He expressed the necessity of modification of the electrode, and he devised one for this purpose. He mentioned in his references the name of Dr. Julio Lopez Lacarrère of Madrid. Shortly after that meeting we travelled to assist in the International Ophthalo mological Congress, held in Madrid, in April, 1933, where we had the chance to see Lacarrère exhibit to the members of the् Congress his operative technique, which he called electro-diafaco (meaning electro-penetration) in cataract extraction, and demonstrate his lecture with a cinematographic film.

He did not, however, operate during the week of the Congress and very few members of the Congress had the opportunity of seeing him operate.

After the Congress was over, I lingered behind in Madrid to be able to visit the hospitals of that city, and in one of these it was rumoured that Dr Lacarrère was to operate on cataracts by his method before a group of American doctors; I had the luck to watch him and saw Professor Emil Krueckman, of Berlin, amongst the group mentioned. Lacarrère did two operations, which were 100 per cent. true extraction after electro-coagulation.

\section{Origin of the Idea}

The attention of the originator was drawn to the use of diathermy in lens extraction from the observations of adhesion of tissues to the electric knife, rather than through cutting, in general surgery due to insufficient current. He proceeded to make use of this surgical inconvenience by experimenting on the clear lenses of rabbits. 

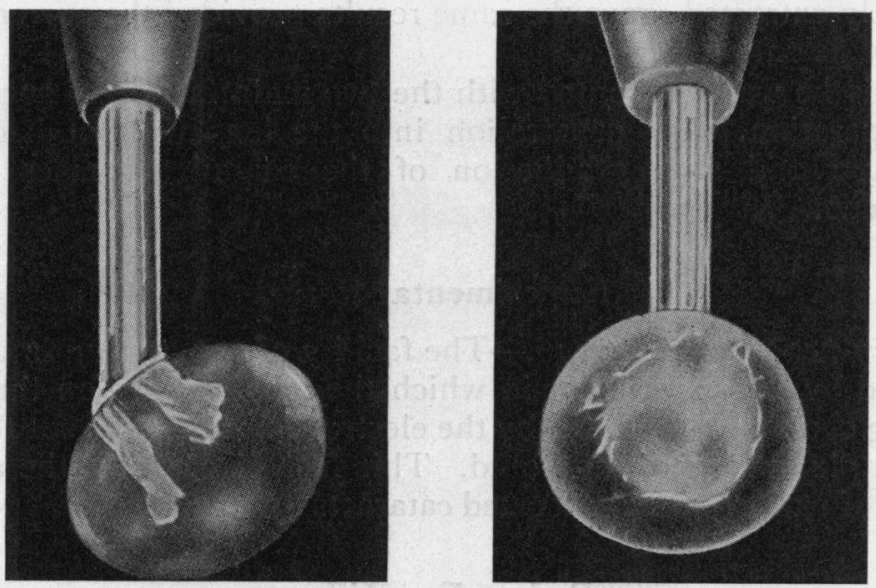

Rabbits' Lens.

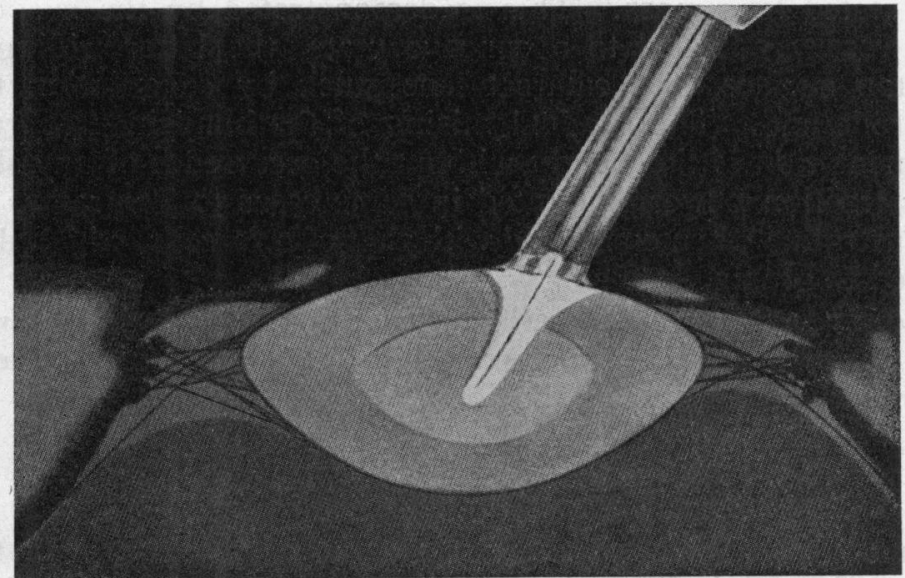

Human Lens.

FIG. 1.

Through these experiments he came across the rather interesting observation, namely, the facility of the penetration of the needle into the mass of the lens.

His primary trials surprised him by this facility of penetration of the needle into the mass of the lens more than did the enormous adherence of the latter to the needle. He attributed these results to the consistence of the normal lenses of the young animals experimented on, but his later experiments on human hard cataracts, 
recently extracted, gave the same results provided the current used was sufficiently intense.

Thus he was confronted with the two main factors of success of his operation, easy penetration into the lens without backward pressure and strong adhesion of the coagulated mass to the electrode.

\section{Experimental Period}

Easy penetration proved.-The facility of penetration is demon- $-\vec{O}$ strated by the experiment in which the lens floating on the white $\vec{\omega}$ of egg could be penetrated by the electrode needles without the lenso being plunged into this liquid. This facility explains the advisability of extraction of dislocated cataracts by this method.

\section{Rosary Experiment}

Another interesting experiment was made by Lacarrère to demon-9 strate the amount of the force of traction of the electrode on the coagulated lens mass. This is demonstrated by the suspension of a rosary attached to a concave plate, the latter, riding over? the top surface of a cataract lens stuck by coagulation to theo electrode end. The gradual raising of the hand insures gradugi augmentation of the weight without the occurrence of any shock ${ }^{\prime} .0$ This traction power amounted in some cases to 70 grams, whighs is illustrative when compared with that of a forceps, which did noto exceed 15 grams.

However, until an experiment is devised to estimate in vivo and during operation the forces that oppose the exit of the lens, the rosary test remains fallacious.

\section{Balance Experiment}

In order to demonstrate the weight of pressure due to the penetration of the wires into the lens and estimate this in figures, Lacarrère did the balance experiment. A cataract lens stuck on a piece of flesh, is put on to one scale of a very delicate balance, balanced to precise level by weights put into the other scale? With the electrode handle fixed perpendicularly to the cataract? just touching its surface, a small weight of 30-50 centigrammes is sufficient to upset the equilibrium of the balance and to provoke a movement which produces the approach of the cataract to the electrode, which latter penetrates it with a minimum force. Asw the resistance of the weakest zonula of an aged patient is calculated to be 2 grams, it follows that luxation of the lens backwards due to the weight of penetration of the electrode wires is improbable. 


\section{Apparatus}

Unlike the case in general surgery, where through repeated cuttings, the required intensity is arrived at, either by decreasing or increasing the intensity of the current, in eye surgery, or more precisely, in cataract extraction, it is essential to fix beforehand the dose required, to avoid insufficient coagulation or affection of the regions neighbouring the place of application of the electrode from over effect. So it was indispensable for Lacarrère

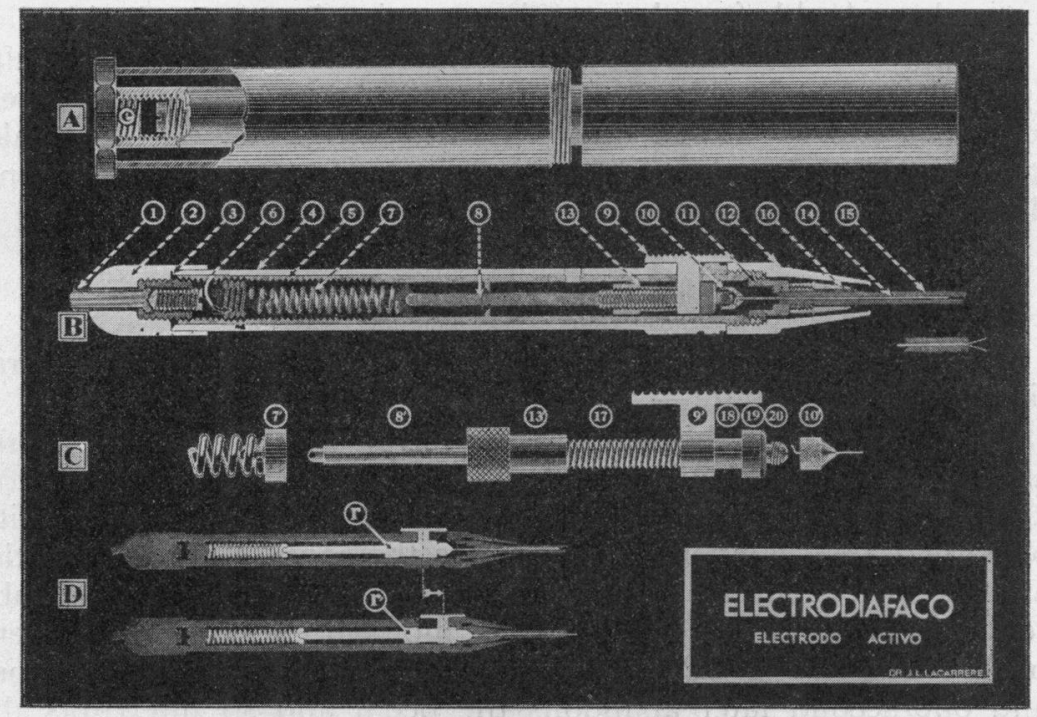

FIG. 2.

to create a technique and adopt an instrument giving a guaranteed constant and equally efficient current.

This he solved by the help of a phantom control, which permits, beforehand, the placing of the rheostat of the apparatus on the exact point which produces the maximum intensity of coagulation required, once for all, through experiments made on animals, and later actually in operations on human lenses.

Lacarrère employed a Siemens apparatus which is furnished with a modification, after his own suggestions, to estimate, beforehand, the amount of the current (about 90 milliampères) required to pass and make its effect on the lens.

His main and more important work, after thinking of utilising diathermy for the extraction of cataract, was to devise an electrodehandle. 


\section{The Electrode Carrier Handle}

The construction of the handle, Fig. 2 , has been very delicate work, because on this, particularly, depends the good result of the operation.

With every apparatus is supplied a handle electrode carrier, with two electrodes; one for the extraction of cataract, the other for the operation of detached retina. These consist, primarily, of an capillary glass tube, inside of which glide one or two steel wires of $0.14 \mathrm{~mm}$. diameter. These metallic wires can be made to protrude outside the glass tube for a distance of about $2 \mathrm{~mm}$., or more $\vec{\omega}$ in single or double form by pressing a spring button on the handle $\frac{\mathscr{O}}{\sigma}$

The electro-diafaco has a foot-interruptor connected to the apparatus by a flexible cable. This permits the operator himself to cut off the current at his own will, at the moment he thinks it right rather than have to depend on, or lose time by, allotting this to his assistant.

\section{Operative Technique}

The operative technique employed in the electro-diafaco opera? tion is the following:-

One first adjusts the wires for a protrusion of $2 \mathrm{~mm}$., or mobe. as required. After having verified, by pressing the control butti and using the rheostat, that the apparatus works to a capacts of 80 or 90 milliamperes, one applies the capillary tube over the anterior surface of the cataract (keeping the wires inside the tube retracted by the handle button), the moment one runs the curren? by pressing the pedal, the operator releases the handle button and one second later abandons the pedal and so interrupts the current. In this manner the cataract is made to adhere to the electrode and so is withdrawn from the eye.

The needles do not, by themselves, penetrate the lens, but the way is opened for them by the electric spark; the lens thus encountering the least pressure as it is pricked by the needles.

When the needles penetrate the lens, a very adherent coagulated cristalline nucleus is formed around them.

"The time of the operation is in practice reduced to almost an instantaneous manœuvre. The slenderness of the glass rod, whic is introduced into the eye, and the great power of apprehensiong of the instrument favours and insures, in such a way, traction rotation or other advisable manœuvre, and makes this metho\& extremely easy, demanding none of the manual dexterity ang fine feeling necessary in the other already known methods."

Fundamental advantages.-The fundamental advantages Lacarrère apparatus and electrodes are :- 
(1) Previous regulation of current.

(2) Fixation of previously measured length of needle allowed to enter the lens substance.

(3) The bifurcation or doubled wires give a surer grip of the lens.

(4) The way the wires enter the lens avoids tearing of capsule contrary to what happens if the wires were stuck to an iron bar.

(5) Perfect isolation. Varnishes used in other electrodes do not offer the same guarantee of insulation as the glass capillary tubc.

\section{Resumè}

The nucleus adhering to the needles forms with them and with the coagulated albuminoid matter, one mass or body. This coagulation so obtained, spreads in a uniform way from the outside to the inside, and laterally to the extent of 2 to $3 \mathrm{~mm}$. from the extremity or end of the metallic wires. It is, consequently, on the whole central mass that it performs the traction of the cataract by means of the electro-diafaco. It can also be said that this method provokes an instantaneous partial electrical maturation of the cataract. In tumescent cataract there are possibly cases whereby the penetration of the needles and the perforation of the capsule may give rise to the exit of almost a liquid mass, but simultaneously the spark that first perforates the capsule immediately coagulates around each needle, in this way closing the whole capsular sac that adheres firmly to the needles and to the coagulated lens matter. In these cases, the lens, so reduced in volume, can be extracted completely with the greatest ease.

However, in some cases the capsule bursts from the boiling of the liquid cortex; the nucleus, when coming out, draws with it some of the soft masses. Thus one remarks the lack of pressure, in contrast to the case in cystotomy, and the fact that the lens matter comes out, drawn by its adhesion to the nucleus and not by pressing the globe. It is sometimes necessary, in spite of this, to wash out the anterior chamber in the usual manner.

\section{Personal Experience}

Taking into consideration that in almost all methods of intracapsular extraction of cataract some pressure has to be exercised, with possible consequent loss of vitreous, one should welcome any procedure that does not comprise pressure on the globe. Lacarrère has shown by his experiments that his method of extraction of the cataract is not only free from pressure on the globe, but also on the lens. 
When I intended to apply this method to some cases of cataract, I tried it on the lenses of pigs' eyes. These are, however, bigger in size than the human lenses but, nevertheless, the method served $\overrightarrow{\vec{\omega}}$ to demonstrate the extent of coagulation in the lens and around the wires, and gave a rough idea about the current sufficient for the effect required. We used a Siemens apparatus (Thermoflux) which we had on trial for some time.

Of course, insufficient current would mean failure to extract $\%$ the lens whereas too much current would lead to shrinkage of the $\vec{\circ}$ lens matter with possible injury to surrounding tissues. Conse- $\overrightarrow{ }$ quently, the success of this operation depends not so much on $\vec{\sigma}$ manual dexterity, as it does on causing the appropriate coagulation. I must here confess that it needs experience, on behalf of the surgeon, to guess his right dosage and duration of current.

I have operated on a few cases of human cataract of which two $\stackrel{\vec{\sigma}}{\vec{g}}$ were exhibited to members of the Ophthalmological Society of $\underset{7}{\sigma}$ Egypt. One of the two cases had keratitis for some time after 9 the operation, probably through over-dosage.

\section{Personal Suggestions regarding Dosage}

As it is taught in diathermy that the actual amount of curreng affecting the site of the operation is influenced by the patient electric resistance, there arises a fallacy in the suggestion of pres viously estimating the dose and fixing it on the apparatus. That is to say, you may in the case of detached retina operation, fix your current at 60 before applying it to the sclera, with the result $\stackrel{\mathbb{D}}{\circ}$ of obtaining either insufficient coagulation or charring. To avoid such unexpected results, I thought of trying the effect of the current away from the field of operation, by applying it to the conjunctiva, for example, beforehand. Then I thought of applying the current to a raw piece of meat, stuck on the forehead of the patient to minimise experimenting on the patient's tissues. The latter test served my purposes. I have not read about it, and I am unaware of its being mentioned in the literature.

Though it was possible in operations other than cataract extractions to prophesy the required amount of electricity, I had to chance it in electro-diafaco. But the fact remains, that in the cases operated upon by Lacarrère himself, in my presence, the lens did come out promptly and unmutilated.

Unfortunately my experience in this subject could not be $\tilde{O}^{\circ}$ extended any further, as the Siemens apparatus had to be returned $\mathrm{\omega}$ to its owners, and my electrode cables do not fit into the Moorfields apparatus, which our hospital possesses. 
BIBLIOGRAPHY

Lacarrère, J. L.-Electrodiaphakia. Klin. Monatsbl, f. Augenheilk., Vol. LXXXVIII, p. 788 (III), 1932.

Zimmerman, C.-Amer. Jl. of Ophthal., Vol. XV, p. 1001, 1932.

Lacarrère, J. L.-Our new method of intracapsular extraction of senile cataract. Electrodiaphakia. Arch. de Oftal. Hisp.-Amer., Vol. XXXII, p. 293 (III), 1932.

Davidson, M.-Amer. Jl. of Ophthal., Vol. XV, p. 1001, 1932.

Lacarrère, J. L.- Cataract extractions by means of the electrophake. Rev. Cubana de Oto-Neuro-Oftal., Vol. I, p. 149, 1932.

Wilde, A. G.-Amer. Jl. of Ophthal., Vol. XVI, p. 178, 1933.

Lacarrère, J. L.-Arch. de Oftal. Hisp.-Amer., Vol. XXXII, p. 293, 1932.

La extracción de la cataracta senil mediante nuestro metodo operatorio de "electrofaquia." La Medicina Iberia, Madrid, 1932.

Nuestra técnica operatoria de la cataracta por "Electrodiafaquia." Revista Oto-Neuro-Oftalinologia, Año 1932.

Ann. d'Ocul., Vol. CLXX, pp. 273-289, 1932.

A rchivos de Oftalmologia de Buenos-Aires, Vol. VII, pp. 323-334, 1932.

Nuestro procedimiento original de extraccion total de la cataracta senil.

La electrodiafaquia. Barcelona, 1932.
Arch. de la Facultad de Medicina de Zaragoza, Nov.-Dec., 1932.

Tobgy, A. F.-Bulletin of the Ophthalmological Society of Egypt, Vol. XXVI, Session 30, p. 20, 1933.

\title{
A VISUAL ACUITY TEST FOR MALINGERERS
}

\author{
BY \\ Lt.-Col. Sir J. N. Duggan, Kt., C.I.E., O.B.E., D.O.(Oxon.) \\ BОМВАY
}

THE malingerer in India is usually illiterate and ignorant. But he has all the more cunning to dodge the examiner and keep him on the fence. Besides, detection of malingerers is much hampered by the dearth of appliances which by systematic manipulation by the surgeon will certainly confuse the patient. This is especially so in India where the malingerer type often has an alert mentality that is quick to take advantage of the simplicity of most of the existing tests, and thus confound the legitimate suspicions of his examiner. I often had to spend long hours in detection of such malingerers, but never had the complete satisfaction of being convinced of their simulation. I have, therefore, longed for a test which could be used successfully with illiterate patients and, while convincing one of their malingering, would also help to determine their visual acuity fairly accurately to enable the surgeon to ascertain the percentage loss of vision. The test $I$ have devised is capable of many variations of the positions and number of the openings in relation to the colours. Moreover, as the apertures are in Snellen sizes from 6/24 to $6 / 6$ it has the additional advantage of being in great measure a visual acuity test. The feature of the 